\title{
Analysis of Nodal Diameter Zero Blade Vibrations of a Radial Turbine ${ }^{\dagger}$
}

\author{
Markus Wunderlich ${ }^{1, *}$, Alexander Esper ${ }^{1}$, Manfred Wirsum ${ }^{1}$ and Klaus Buchmann ${ }^{2}$ \\ 1 Institute of Power Plant Technology, Steam and Gas Turbines, RWTH Aachen University, Templergraben 55, \\ 52056 Aachen, Germany; esper@ikdg.rwth-aachen.de (A.E.); office@ikdg.rwth-aachen.de (M.W.) \\ 2 Kompressorenbau Bannewitz GmbH, 01728 Bannewitz, Germany; Klaus.Buchmann@kbb-turbo.com \\ * Correspondence: wunderlich@ikdg.rwth-aachen.de \\ $+\quad$ This paper is an extended version of our paper published in the Proceedings of the 13th European \\ Conference on Turbomachinery Fluid Dynamics and Thermodynamics, Lausanne, Switzerland, 8-12 April \\ 2018; Paper ID: ETC2019-138.
}

Received: 6 February 2020; Accepted: 30 June 2020; Published: 9 July 2020

check for updates

\begin{abstract}
This paper presents results of strain gauge measurements, which have been carried out on a full-scale turbocharger test rig. Rotational speed of the turbocharger was ramped up and down through four preliminary anticipated rotor-blade resonances, with a known combination of main order of excitation and corresponding nodal diameter. An analysis of the transient data is presented. An investigation of spectra with high frequency resolutions, centered on individual blade resonance points in time, is presented. In contrast to former research, all blades resonate at the same point in time and thus at the same resonance frequency, if the excitation corresponds to a nodal diameter of zero. Strain data from the shaft is used to support findings, which, in other publications, often solely rely on strain data from individual blades.
\end{abstract}

Keywords: radial turbine; engine order; phase; strain gauges; vibration

\section{Introduction}

As already theoretically described in Refs. [1,2], the potential effect as a result of the passing rotor blades, as well as the stator blade wake are the two causes for transient blade forces and hence the two main excitation mechanisms for rotor-blade vibrations in stator-rotor assemblies in axial turbines. Ref. [3] demonstrated the applicability of those theoretical assumptions on a radial turbine wheel, using only two strain gauges on opposite blades. A deeper investigation of a larger number of blades, with a direct measurement system like strain gauges, during resonance operation is not yet present in the literature. Furthermore, detailed studies of the shaft vibrations during resonance occurrence in rotor blades, using direct vibrational measurement systems, has not been published yet. Ref. [4] describes the most common experimental measurement techniques for measuring blade vibrations in rotating machinery. They emphasize the use of-however intrusive-strain gauges on blades, to get a full picture of their vibrational behavior. Regarding the influence of strain gauge application on resonance frequencies and maximum displacements, Ref. [5] investigated two axial turbine BLISKs (stages 1 and 6) of a test-compressor. An influence of the manner of strain gauge application is experimentally shown. High-temperature strain gauges, typically applied using temperature resistant ceramic cement, have a more significant influence on the vibrational behavior of the blades, compared to standard foil strain gauges. The ceramic cement stiffens the respective blade on which the strain gauge is applied, increasing its so-called bladealone frequency up to $(2.5 \%)$ compared to its frequency prior to the application. Furthermore, the forced response resonance frequencies of all blades, not only blades with a gauge, are affected by the application. While the maximum displacements are not 
significantly influenced, displacement ratios between instrumented and non-instrumented blades shifted. Due to the stiffening of the structure, deflections of instrumented blades shifted towards local minima, while non-instrumented ones showed larger deflections. Refs. [6,7] investigated flow-induced blade vibrations in radial turbines without guide vanes, using newly developed numerical approaches and different experimental measurement techniques.

This paper presents the results of strain gauge measurements on the rotor blades of a radial turbine wheel in a turbocharger. Six high-temperature strain gauges were placed at the same relative position on the rotor blades, evenly distributed in circumferential direction over all 12 blades. The rotational speed of the turbocharger was ramped through four preliminary anticipated resonance points, with a known order of main excitation through the stator blade count of 24 . Excitability of the four individual modes through excitation order 24 (EO24) was theoretically verified using the well-known interrelationship between excitation order, number of blades and resulting nodal diameters derived in Ref. [8]. In this paper, blade responses during excitation of vibratory modes M5, M6, M8 and M9 with the help of strain data from both the shaft and the blades is presented. As mentioned above and with the slight exception of M8, the excitation of vibration patterns in nodal diameters of zero (ND0) is proven. Here, in contrast to reports from the literature, no frequency mistuning could be observed at all. As long as the nodal diameter of zero is strongly pronounced, hence all blades oscillate in phase, all maximum blade deflections and strains occur at the same respective rotor speed. Thereafter investigations of two additionally present excitation orders (EO17 and EO16), which appeared during the measurements, are presented. These excitation mechanisms appeared at rotor speeds below M8EO24 and above M9EO24.

\section{Experimental Investigations}

The test turbocharger, provided by Kompressorenbau Bannewitz GmbH (KBB), is designed for usage in marine engine applications. It was implemented into the test stand at the testing facility of the Institute for Power Plant Technology, Steam and Gas Turbine and powered by a six-stage high pressure radial air compressor. The turbine inlet temperature, which was held steadily at $500^{\circ} \mathrm{C}$, was achieved by a natural gas operated air preheater. For details on the general setup of the turbocharger, used performance measurement technologies and the implementation at the testing facility of the institute, see Ref. [9]. Table 1 lists the test rig geometry and boundary conditions.

Table 1. Test rig geometry and measurement boundary conditions.

\begin{tabular}{lc}
\hline Turbine hub to tip ratio & 0.29 \\
Maximum rotational speed & $40,000 \mathrm{RPM}$ \\
Turbine inlet temperature & $500^{\circ} \mathrm{C}$ \\
Maximum compressor volumetric flow rate & $4.2 \mathrm{~m}^{3} / \mathrm{s}$ \\
Maximum compressor pressure ratio & 5.6 \\
\hline
\end{tabular}

The test object, a radial inflow turbine with 12 blades, was equipped with a total of eight strain gauges (due to limitations of the telemetry system), six of them being high-temperature (HT) strain gauges (SG) and two standard foil strain gauges. All six HT gauges have been applied to the same relative blade position on every other blade (on the respective suction side), as illustrated in Figure 1a. Two opposite blades have also been applied with high-temperature strain gauges on the pressure side. Unfortunately, data from those gauges could not be evaluated thoroughly, as connection to them was lost in early stages of the measurements. Relative positions were chosen in a way to cover high surface strains and coincidentally low strain gradients for all vibratory modes to be investigated.

In Ref. [10], the effect of transient sweeps through blade resonances on their resulting vibration amplitudes was investigated. They derived a limit for rotational acceleration without influencing resonance amplitudes:

$$
\frac{\partial N}{\partial t} \leq \frac{60}{\mathrm{EO}} \zeta_{k}^{2} f_{\mathrm{M}_{k}}^{2}
$$


During all measurements, sweep accelerations were performed well below this limit.

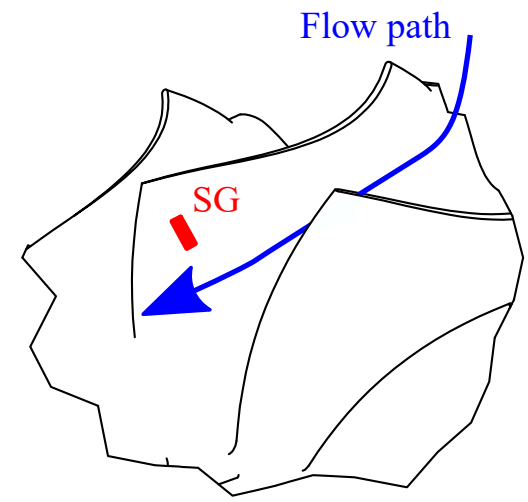

(a)

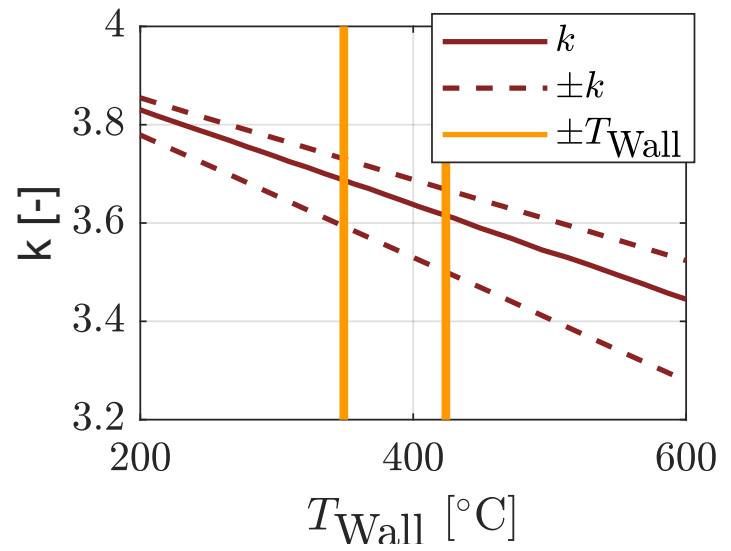

(b)

Figure 1. Positioning and temperature sensitivity drift of high-temperature strain gauges. (a) Relative blade position of a high-temperature strain gauge (SG) on the suction side of one blade; (b) Nominal sensitivity and sensitivity uncertainty (specified by the manufacturer) over temperature.

Additionally, as mentioned above, two standard foil strain gauges have been applied to the shaft, at a centered position between the bearings. The principal axes of both SGs are twisted $45^{\circ}$ to the rotational axis of the shaft, thus enabling the differentiation of bending- and torsional vibrations. A bending vibration of the shaft results in a phase lag between these gauges of $\Delta \Phi_{S}=180^{\circ}$, whereas torsional vibrations result in in-phase signals. The phase lag between two strain signals $y_{1}$ and $y_{2}$ is:

$$
\Delta \Phi_{1,2}=\operatorname{atan} \frac{\operatorname{IM}\left(\mathcal{F}\left(y_{1}\right) / \mathcal{F}\left(y_{2}\right)\right)}{\operatorname{RE}\left(\mathcal{F}\left(y_{1}\right) / \mathcal{F}\left(y_{2}\right)\right)}
$$

where $\mathcal{F}$ denotes the Fourier transform of $y$ and IM and RE denote the imaginary and real part of the resulting complex number vector. A commercial telemetry system, consisting of a total of ten SG channels with a sampling rate of $50 \mathrm{kHz}$ was used. Due to sensitivity (see Figure 1b, the displayed wall temperature range was numerically calculated) drifts, uncertainties in the SG supply current and the given maximum signal to noise ratio of $39 \mathrm{~dB}=98.878 \%$, measured strain amplitudes are prone to an error of $\pm 5 \%$. Electrical resistance of all gauges was measured using the telemetry system, which can modulate the supply current with a defined frequency and amplitude. Resistances increased up to $10.8 \%$ during warm up of the turbine.

All main results of the corresponding FVV research project are presented in Ref. [9]. This project focused mainly on the comparison of maximum strains and blade deflections between the also implemented blade tip timing measurements, strain gauge measurements and numerical aeroelastic calculations during resonance. A more detailed analysis of the strain data-including data from the shaft—is presented here.

\subsection{Experimental Results ND0 Vibrations}

In this section, strain results of all mainly excited vibratory modes are presented. The excitation order 24 is equal to the number of stator blades. Hence, nodal diameters of all main blade responses are $\mathrm{ND} 0$ in an ideal system, at least at the numerically anticipated resonance points with an excitation order of 24. The rotational speed of the turbocharger was ramped through the numerically calculated points of blade resonance, with $\approx 2000$ RPM between the first and the last measurement of each resonance point. Numerical models, which were used to calculate resonance frequencies are described in Ref. [11] (CFD) and in Ref. [12] (FEM). 


\subsection{Blade Vibration Analysis}

During the measurements, several vibratory modes were excited due to EOs unequal to 24, with comparatively small resulting excitation forces, leading to more or less minor blade reactions. Table 2 shows an overview of theoretically expected, measurable blade phase lags in a tuned rotor with 12 blades. $\varphi_{\mathrm{fw}}$ and $\varphi_{\mathrm{bw}}$ are forward and backward rotating nodal diameters (in the rotating coordinate system), $\Delta \Phi_{i, i+2, \mathrm{fw}}$ and $\Delta \Phi_{i, i+2, \mathrm{bw}}$ are the respective measured phases on the blades. An overview of all expected points of resonance is shown in numerically calculated ZZENF diagrams, which are displayed below. For a detailed explanation of ZZENF, or SAFE-diagrams refer to Ref. [13].

Table 2. Forward and backward inter blade phase angle $\varphi$ and measurable blade phase angle between SG-applied blades $\Delta \Phi_{i, i+1}$.

\begin{tabular}{ccccc}
\hline $\mathbf{N D}$ & $\boldsymbol{\varphi}_{\mathrm{fw}}\left[^{\circ}\right]$ & $\boldsymbol{\varphi}_{\mathbf{b w}}\left[^{\circ}\right]$ & $\Delta \boldsymbol{\Phi}_{i, \boldsymbol{i}+2, \mathrm{fw}}\left[^{\circ}\right]$ & $\boldsymbol{\Delta} \boldsymbol{\Phi}_{i, \boldsymbol{i}+2, \mathbf{b w}}\left[^{\circ}\right]$ \\
\hline 1 & 30 & -30 & 60 & -60 \\
2 & 60 & -60 & 120 & -120 \\
3 & 90 & -90 & 180 & -180 \\
4 & 120 & -120 & -120 & 120 \\
5 & 150 & -150 & -60 & 60 \\
6 & 180 & -180 & 0 & 0 \\
\hline
\end{tabular}

Figure 2a,b mark the mainly excited Modes at ND0 in the ZZENF diagram, with their corresponding rotational speed lines. Since the main excitation mechanism is of order 24 and the number of rotor blades is 12, the excitation of ND0 vibrations (excited modes are encircled in red) becomes apparent. Both ZZENF diagrams contain the computed resonance frequencies of the corresponding mode families. Furthermore, Figure $2 \mathrm{~b}$ displays the interference of the rotational speeds exciting M8 and M9 with mode family 5 at nodal diameters 4 and 5 . Both of those resonance occurrences, could be verified experimentally and a more detailed analysis of EO17 will be shown later in this paper.

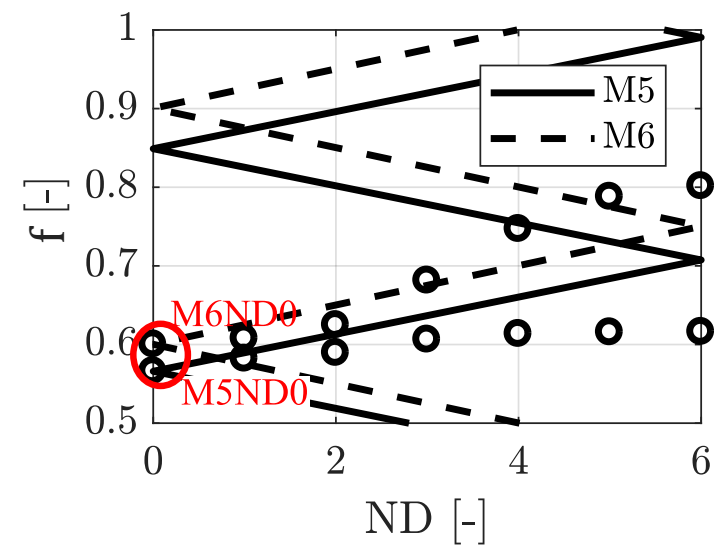

(a)

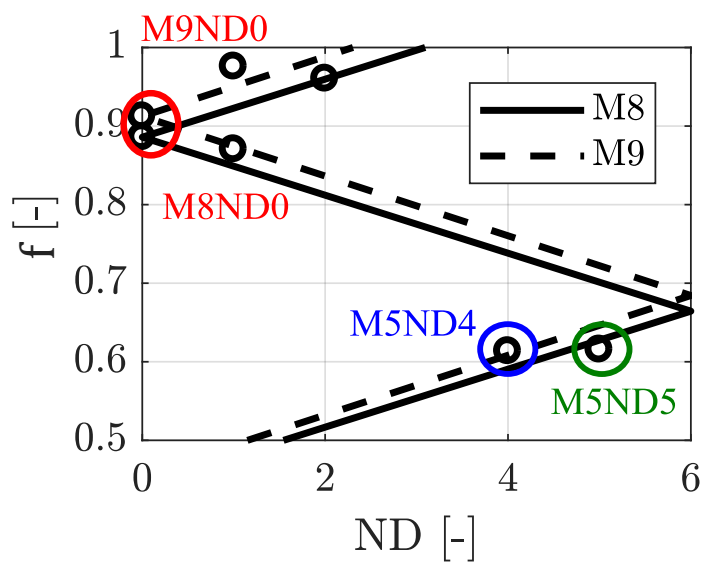

(b)

Figure 2. Numerical ZZENF Diagrams. (a) ZZENF diagram with rotational speeds of M5 and M6 (excitation at EO24 and ND0); (b) ZZENF diagram with rotational speeds of M8 and M9 (excitation at EO24 and ND0).

\subsubsection{M5, M6, M9}

Figure 3a displays normalized strains of all SG-applied blades during one resonance crossing of vibratory mode 5 in the normalized frequency domain. FFTs were computed using a window of two seconds, centered around the maximum strain amplitude in the time domain. Strains are normalized by the maximum measured strain value for all blades and in the displayed frequency 
range. Frequencies are normalized by the excitation frequency of EO24 at maximum rotor rotational speed. The corresponding phase lag of all blades with respect to their next SG-applied respective neighbor, $\Delta \Phi_{i, i+2}$, is additionally displayed in Figure $3 \mathrm{~b}$. As is shown, resonance occurs at the same frequency on all blades. This frequency corresponds to EO24 and hence ND0, which is in line with the measured phase lags of $\Delta \Phi_{i, i+2} \approx 0^{\circ}$ (Figure 3b). Vibrational modes 6 and 9 show an equal behavior to M5. All blade resonance points lie at the same resonance frequency (Figure 4) and an assignment of ND0 is possible, since $\Delta \Phi_{i, i+2} \approx 0^{\circ}$. Maximum phase lags differ about $\pm 1.7^{\circ}(\mathrm{M} 6)$ and $\pm 3.8^{\circ}(\mathrm{M} 9)$. Additionally, a higher amplitude mistuning in mode 6 can be observed. Mode 9 does not show a resonance peak as dominant as the other modes, which may one the one hand be a consequence of the relatively large time window of two seconds, which was used to compute this frequency spectrum and on the other hand be an inherent feature of mode 9 .

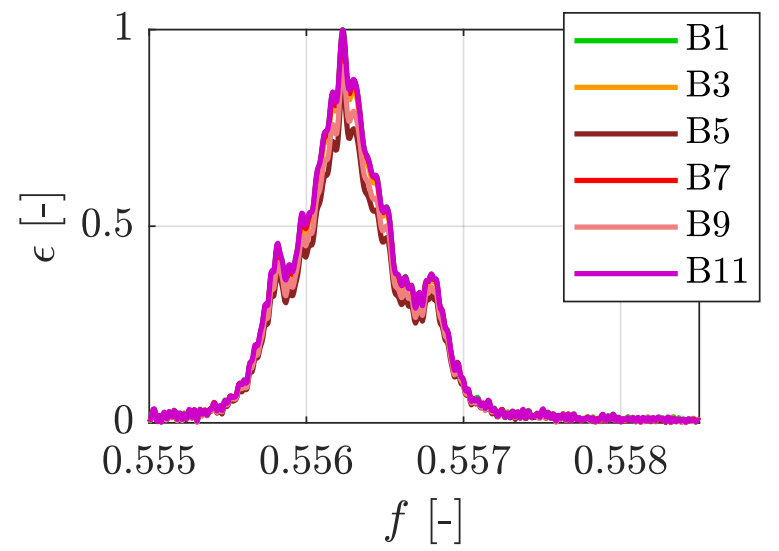

(a)

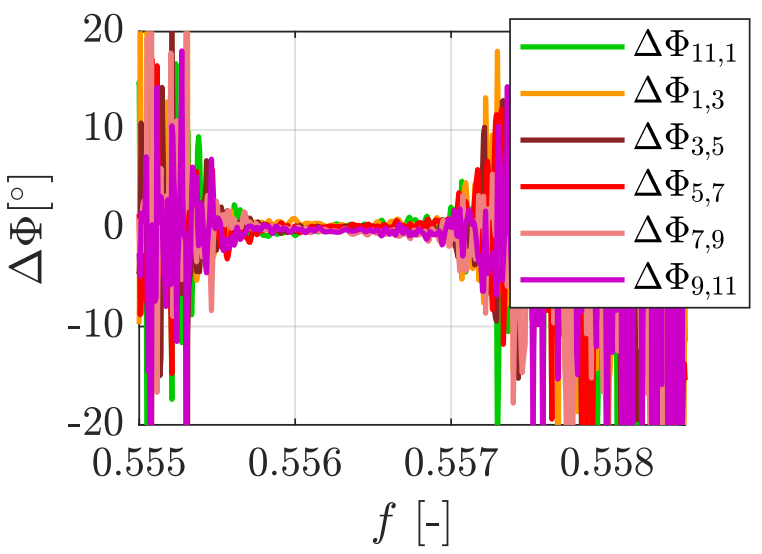

(b)

Figure 3. Vibratory Mode 5: Frequency domain and phase lag. (a) Normalized amplitude of all SG-applied blades during resonance M5; (b) Phase lag of all SG-applied blades during resonance M5 in the frequency domain.

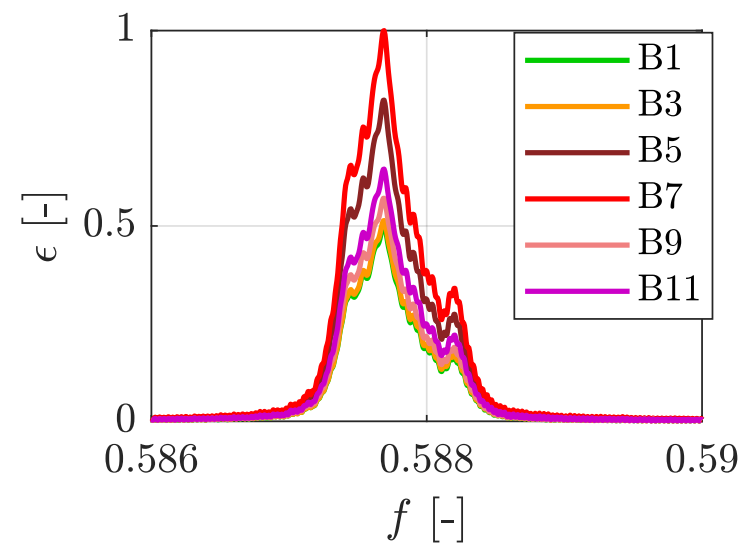

(a)

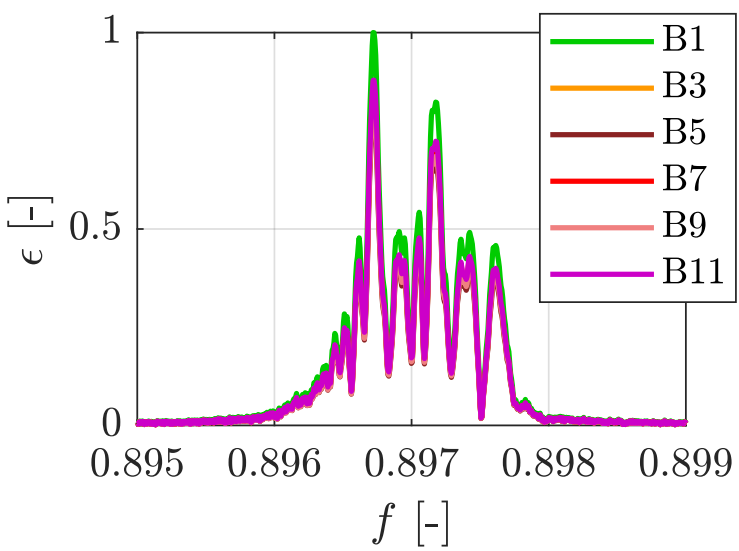

(b)

Figure 4. Vibratory Modes 6 and 9: Frequency domain. (a) Normalized amplitude of all SG-applied blades during resonance M6; (b) Normalized amplitude of all SG-applied blades during resonance M9.

\subsubsection{Mode 8}

Mode 8 showed a somewhat different behavior, compared to M5, M6 and M9. In Figure 5, normalized strains of EO24 blade responses during resonance were extracted from short time Fourier transformations with Hanning windows of $76 \mathrm{~ms}$ and $50 \%$ overlap in time. A clear distinction of the resonance rotational speeds of blades 1,3,11 and blades 5, 7 and 9 is possible (see Figure 5, encircled in 
red). Also, the resonance frequency of all blades differs (dashed lines in Figure 5) slightly. In M8, blades generally responded with the highest absolute strains and deflections compared to the other vibratory modes. Figures 6 and 7 display frequency and phase lag distributions in a two seconds time window, centered at both maxima, $\Omega=0.8744$ and $\Omega=0.8783$, respectively. Due to the maximum frequency resolution of $0.5 \mathrm{~Hz}$ in Figures 6 and 7, some spectral leakage is visible in both frequency spectra. Nonetheless, differences to previously described modes M5, M6 and M9 are apparent. The occurrence of M8 is split into two distinct rotational speeds, at which the SG-applied blades resonate. Furthermore, strains throughout the resonance are less uniform compared to M5 and M6 and multiple local maxima occur in all blades. Considering the phase lags, blade 5 shows an interesting behavior (Figure $6 \mathrm{~b}$ ). It does not show a local maximum at $\Omega=0.8744$, but rather oscillates with a phase lag of $\Delta \Phi_{5,7}=180^{\circ}$ or $\Delta \Phi_{3,5}=-180^{\circ}$ compared to its direct neighbors. In contrast to this, blade 5 shows the highest strains compared to all other blades at $\Omega=0.8783$. At that point, all blades oscillate in phase (see Figure $7 \mathrm{~b} \rightarrow \mathrm{ND0}$ ).

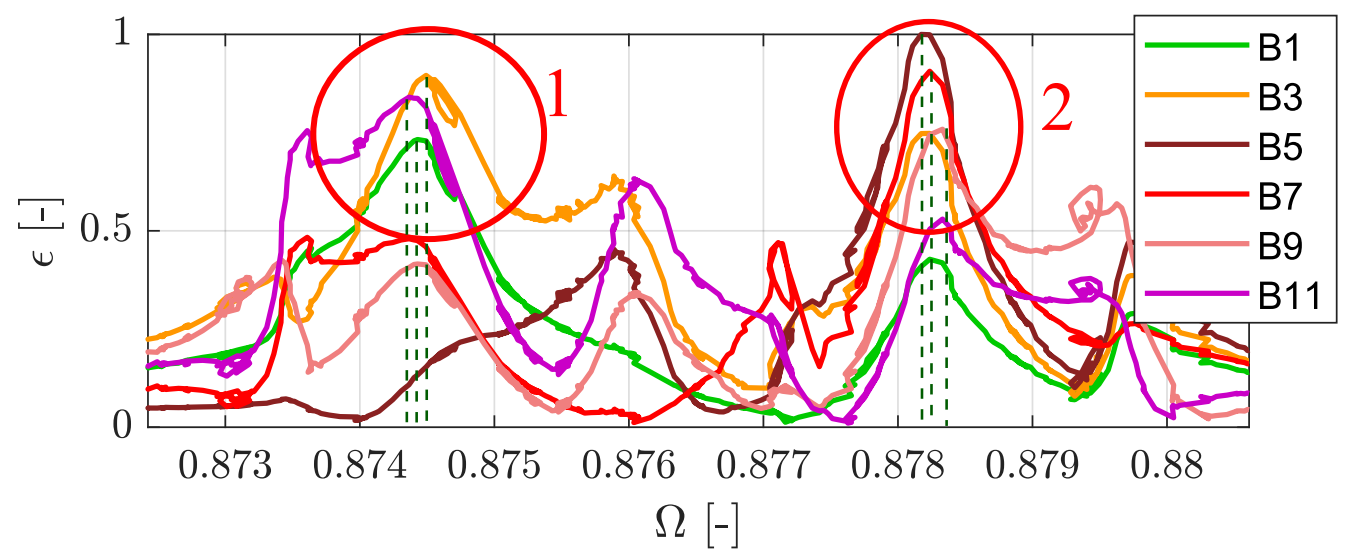

Figure 5. Normalized strain over normalized rotational speed during M8 excitation for all SG-applied blades.

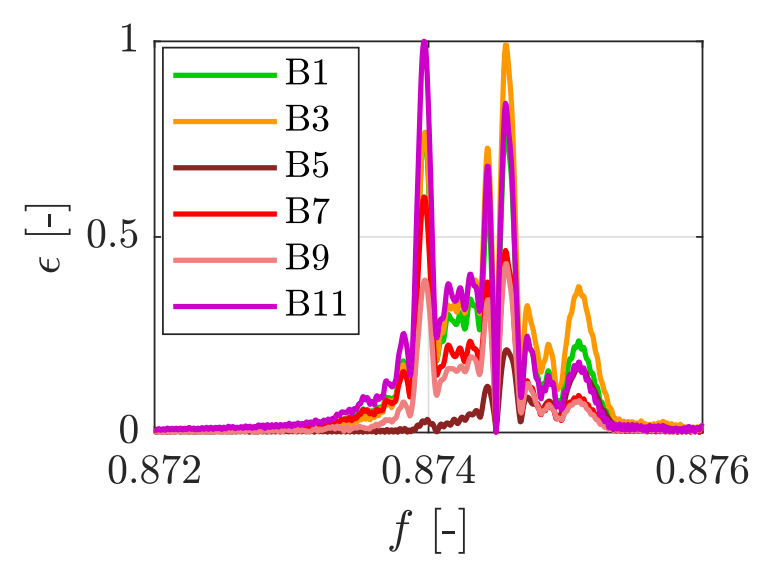

(a)

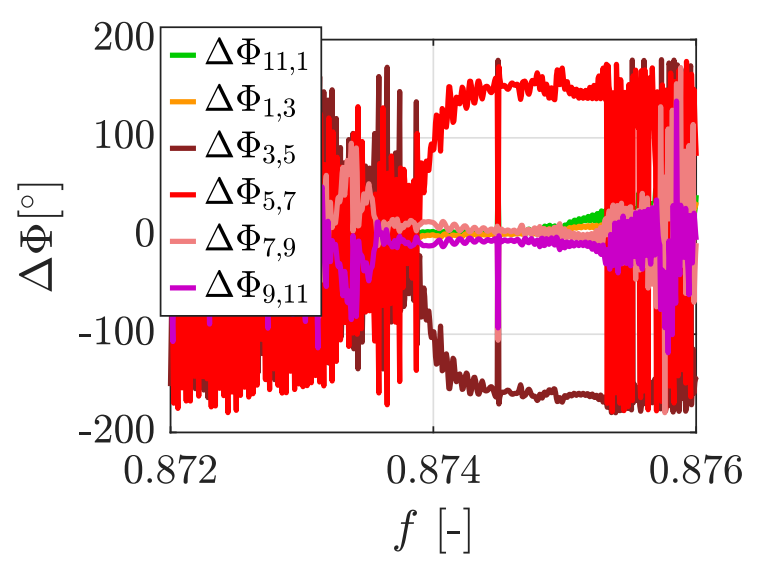

(b)

Figure 6. Vibratory Mode 8-1: Frequency domain and phase lag. (a) Normalized amplitude of all SG-applied blades during resonance M8-1; (b) Phase lag of all SG-applied blades during resonance M8-1 in the frequency domain.

This distribution, or rather split of resonance frequencies has also been observed in Ref. [14]. Neighboring blades with the same or very similar resonance frequencies tended towards the same rotational resonance speed, which in this case holds true as well, since the described blades with almost equal points of resonance lie physically closest to each other. 


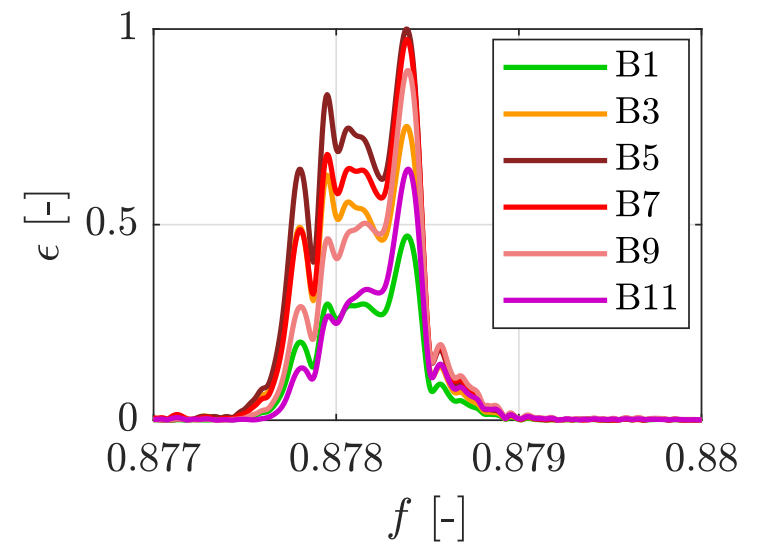

(a)

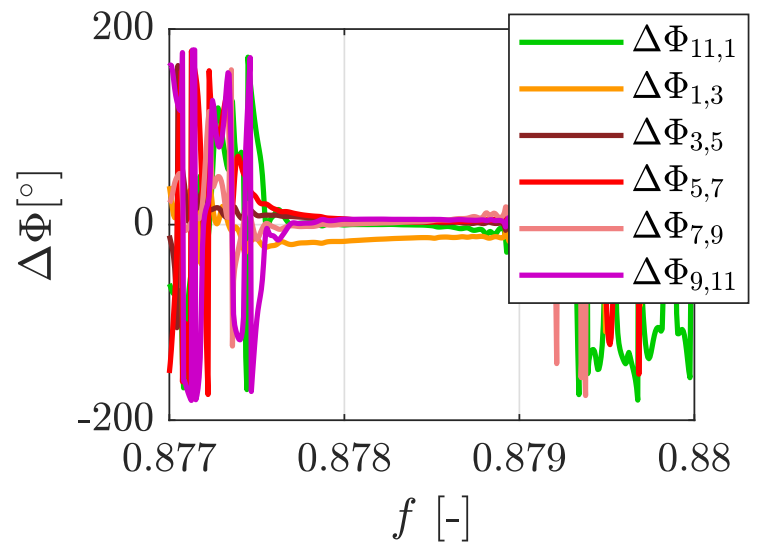

(b)

Figure 7. Vibratory Mode 8-2: Frequency domain and phase lag. (a) Normalized amplitude of all SG-applied blades during resonance M8-2; (b) Phase lag of all SG-applied blades during resonance M8-2 in the frequency domain.

\subsection{ND0 Shaft Oscillations}

In this section, experimental strain data from both SGs on the shaft is presented. Beginning with the lowest responding mode M5, Figure 8 shows strain amplitude and phase lag of the shaft SGs, using the same time window as for the SGs on the blades (Figure 3).

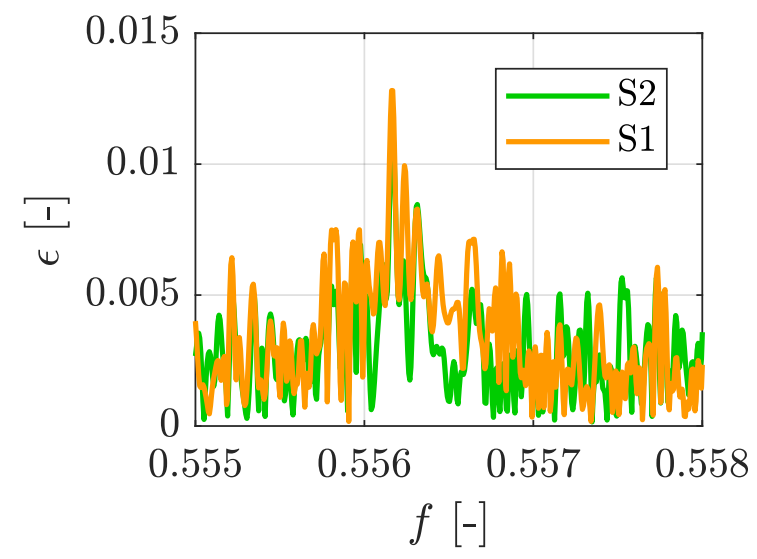

(a)

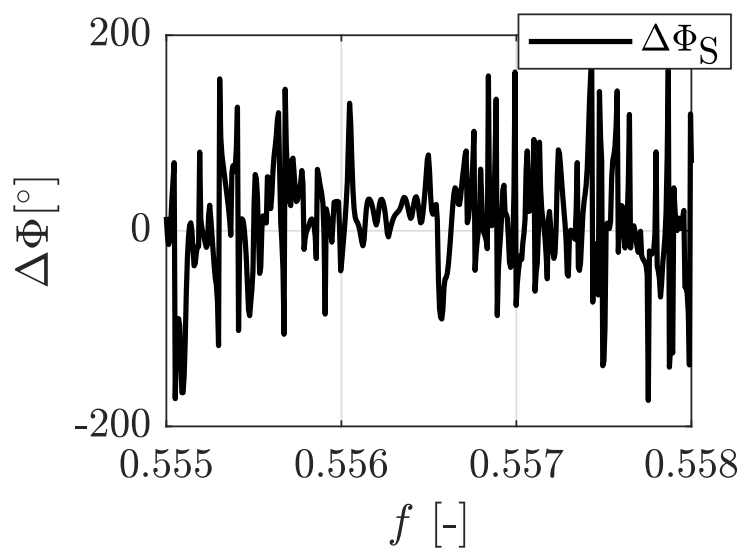

(b)

Figure 8. Vibratory Mode 5: Shaft vibrations, frequency domain and phase lag. (a) Normalized amplitude of both shaft SGs during resonance M5; (b) Phase lag $\Delta \Phi_{\mathrm{S}}$ of shaft SGs during resonance M5.

As a result of the low excitation of M5, EO24 vibrations in the shaft are barely distinguishable from general noise, when only considering the amplitude spectrum (Figure 8a). By computing the phase lag between the SGs on the shaft however (Figure 8b), a clear shift towards $\Delta \Phi_{\mathrm{S}}=0^{\circ}$ can be observed in the region of $0.5555 \leq f \leq 0.557$, which corresponds to the blade vibration frequency of M5 during EO24 excitation. This shift is also visible in the frequency spectrum of M6, M8 and M9 (Figure $9 a, b$ and Figure 10a,b). The expected torsional vibrations in the shaft, due to the ND0 vibration pattern of the blades, are hereby verified. ND0 vibrations theoretically induce a torsional vibration on the shaft, since all blades vibrate in the same direction at the same time, hence exerting a force in circumferential direction, which is translated into the shaft. Figure 10a,b show phases of the shaft SGs during M6 and M9 excitation, respectively. In these cases, a clear shift towards $\Delta \Phi_{\mathrm{S}}=0^{\circ}$ is also visible. During M9, $\Delta \Phi_{\mathrm{S}}$ is shifted towards $-20^{\circ}$. This is a consequence of the ever so slight phase lag of the blades during the excitation of M9, as mentioned in section 'M5, M6, M9'. Due to this phase lag, 
the uniform amplitude distribution and the high rotational energy in the system at this high rotational frequency exert a high influence on the shaft and its vibratory pattern.

Due to the already mentioned deviations of $\Delta \Phi_{i, i+2}$ from zero, a uniform torsional vibration during EO24 excitation is not induced in the shaft. The amplitude spectra of M6 and M9, which are not shown here, are very similar to the spectra of the blades. Due to the much higher blade responses in these cases, shaft vibrations would also be unambiguously identifiable solely from these spectra. Amplitude and phase lag during M8EO24 excitation are displayed in Figure 9. Like before, FFTs were centered around the two resonance points, displayed in Figure 5. A time window of 15 seconds was used in this case, to include all occurring frequencies during the resonance. Even though blade 5 does not resonate in phase with the other blades in case of the first resonance rotational speed, the phase lag of the SGs on the shaft shifts towards zero, indicating torsional vibrations, excited through ND0 vibrations of the blades.

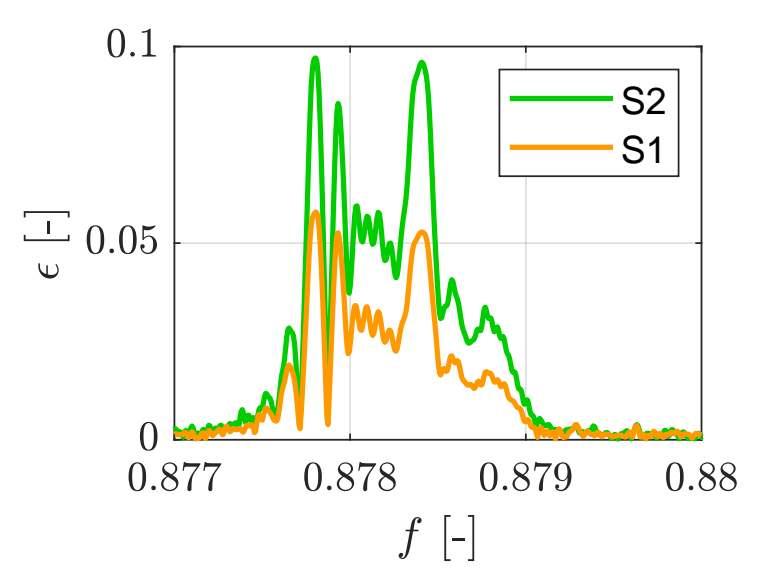

(a)

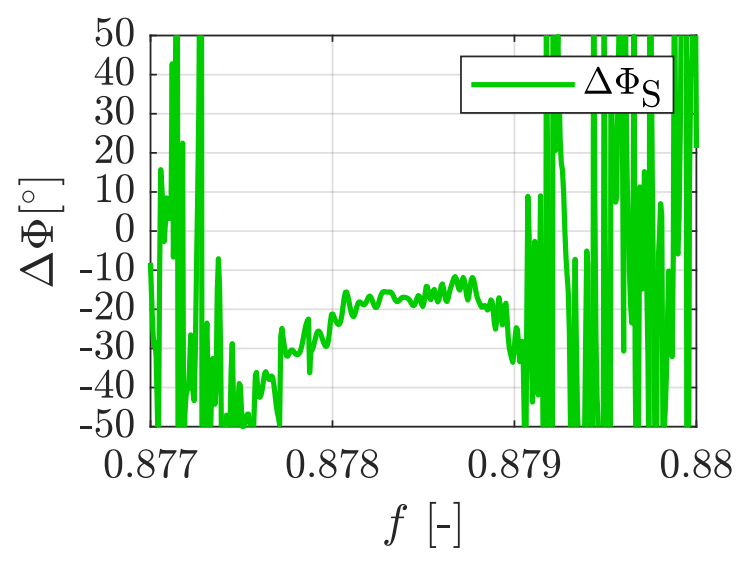

(b)

Figure 9. Vibratory Mode 8-2: Shaft vibrations, frequency domain and phase lag. (a) Normalized amplitude of both shaft SGs during resonance M8-2; (b) Phase lag $\Delta \Phi_{\mathrm{S}}$ of shaft SGs during resonance $\mathrm{M} 8-2$.

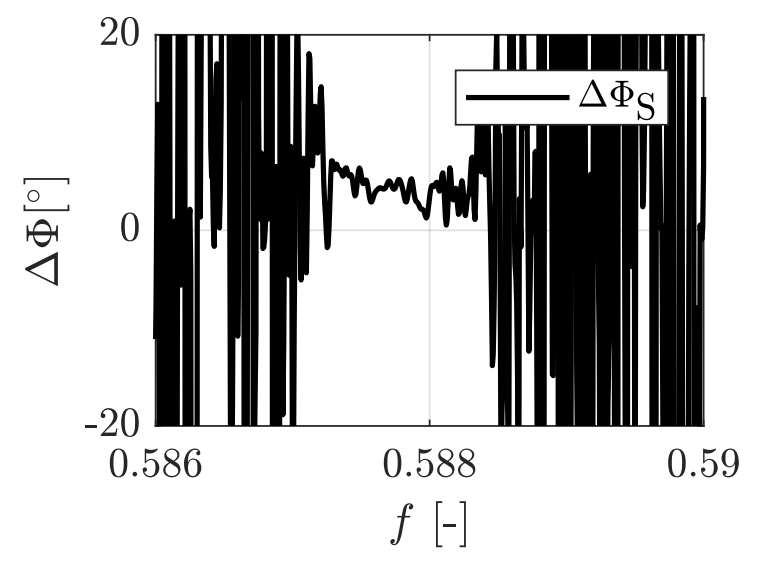

(a)

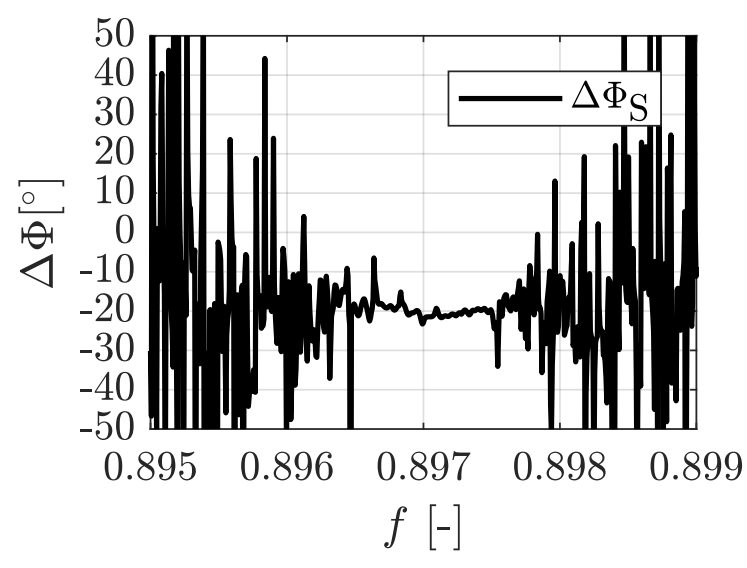

(b)

Figure 10. Vibratory Modes 6 and 9: Shaft vibrations, frequency domain and phase lag. (a) Phase lag of both shaft SGs during resonance M6 in the frequency domain; (b) Phase lag $\Delta \Phi_{\mathrm{S}}$ of shaft SGs during resonance M9.

Furthermore, strain data from the shaft may be used to analyze lower order vibration patterns during operation. During all measurements, frequency content at $f=0.0215$ appeared in the shaft SGs (Figure 11a). By analyzing the phase of the shaft SGs at this frequency (Figure 11b), torsional vibrations in the shaft are revealed. This frequency corresponds to the first torsional Eigenfrequency of the shaft, 
which has been numerically calculated beforehand. The second spike in Figure 11a at $f=0.0245$ corresponds to the rotational speed of the shaft, hence EO1 vibrations, and was also visible during all measurements. Again, the phase lag of the shaft SGs supports this assumption, since $\Phi_{\mathrm{S}}=-180^{\circ}$ at the respective frequency. As stated above, this phase lag corresponds to bending vibrations of the shaft and is a result of residual rotor unbalance, resulting in EO1 excitation.

The deviation from $\Delta \Phi_{\mathrm{S}}=0^{\circ}$ increases with increasing phase difference of blade 5 , starting at around $f=0.874$ (see Figure $6 \mathrm{~b}$ ), which shows the strong influence of even only one blade, on resulting vibrations in the shaft.

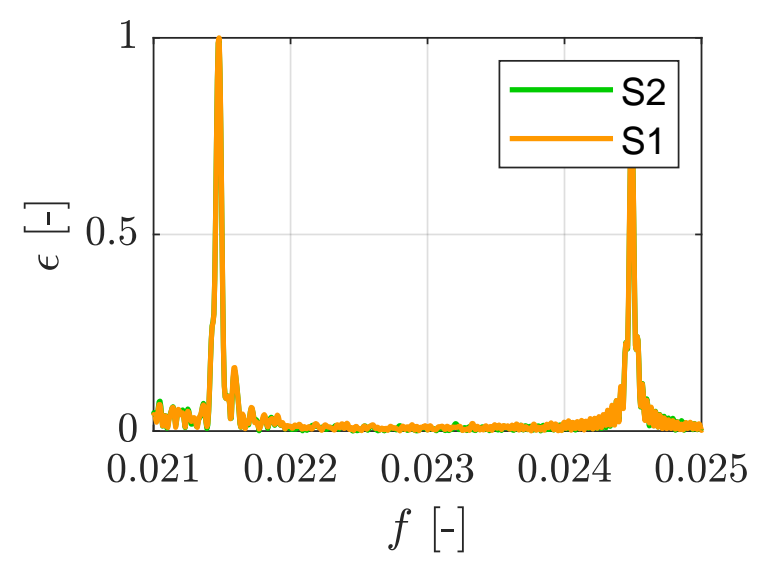

(a)

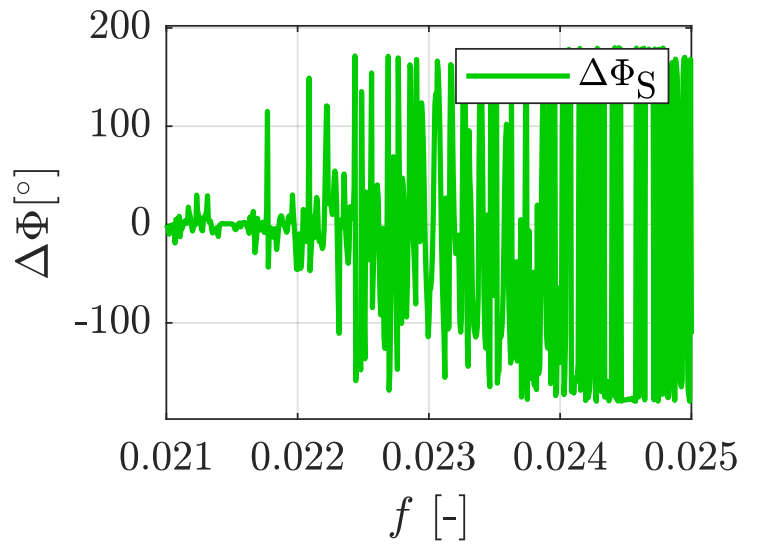

(b)

Figure 11. Vibratory Mode 6: Shaft vibrations, frequency domain and phase lag (low order vibrations). (a) Normalized amplitude of both shaft SGs during resonance M6 (low order vibrations); (b) Phase lag $\Delta \Phi_{\mathrm{S}}$ of shaft SGs during resonance M6 (low order vibrations).

\section{3. $\mathrm{ND} \neq 0$ Vibrations}

In this section, blade vibrations, excited through engine orders other than 24 are briefly described to demonstrate the ability of the presented arrangement of strain gauges to detect such vibration patterns. As shown before in Figure 2b, the excitation of M5ND5 through EO17 is theoretically possible in the same region of rotational speed, as M8 is excited by EO24. EO17 is of special interest here, since the number of vanes in the diffuser of the compressor of the turbocharger is also 17. Thus, M5ND5, encircled in green, is analyzed here. During the measurements, blades were indeed excited by EO17, resulting in measured strains in the frequency region of M5 at higher nodal diameters (see ZZENF diagram, Figure 2a). Frequencies around $f=0.611$ in Figure 12 are a result of EO17 excitation. A zoom into this region is displayed in Figure 13. Along with this, the phase lag of all blades is displayed as well.

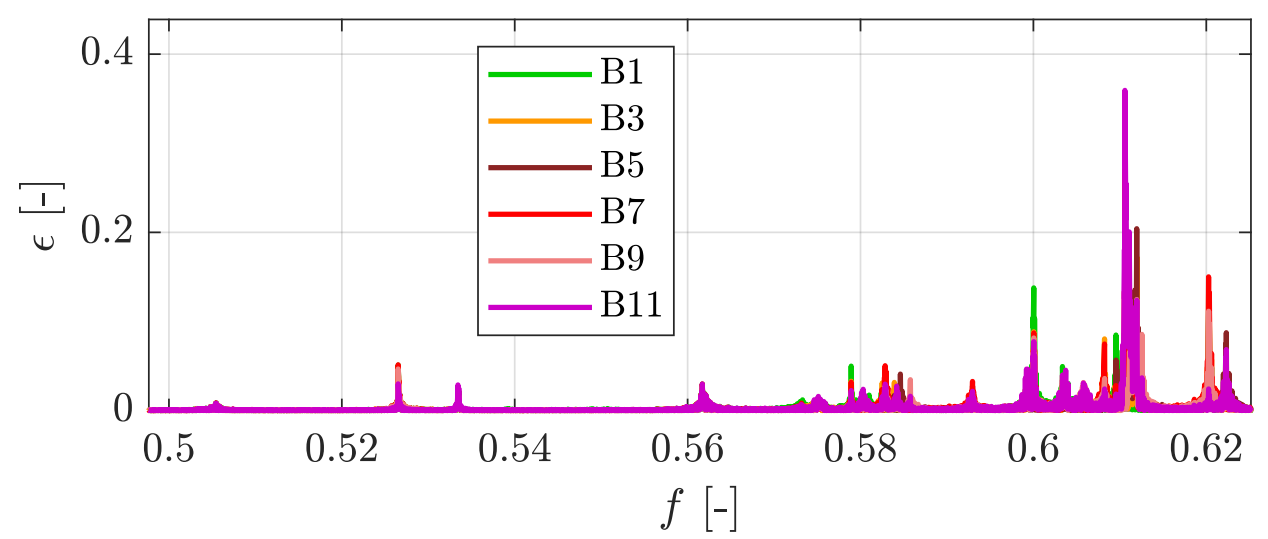

Figure 12. Overview of EO17 frequency region during M8EO24 resonance occurrence. 


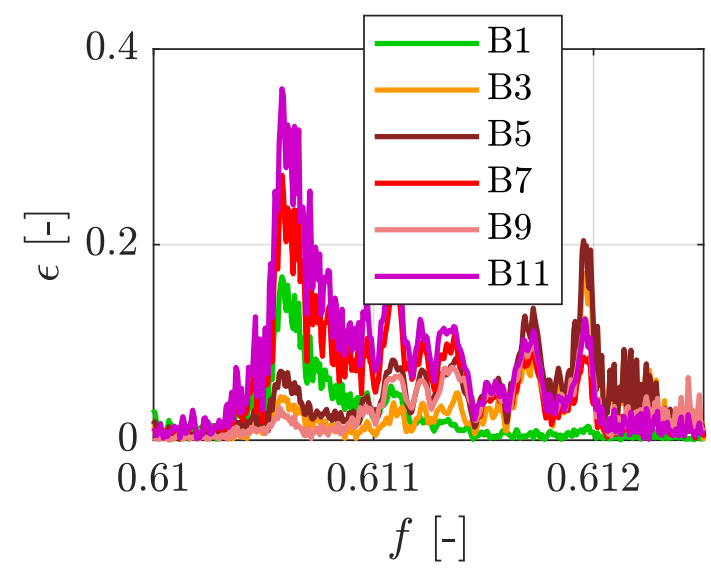

(a)

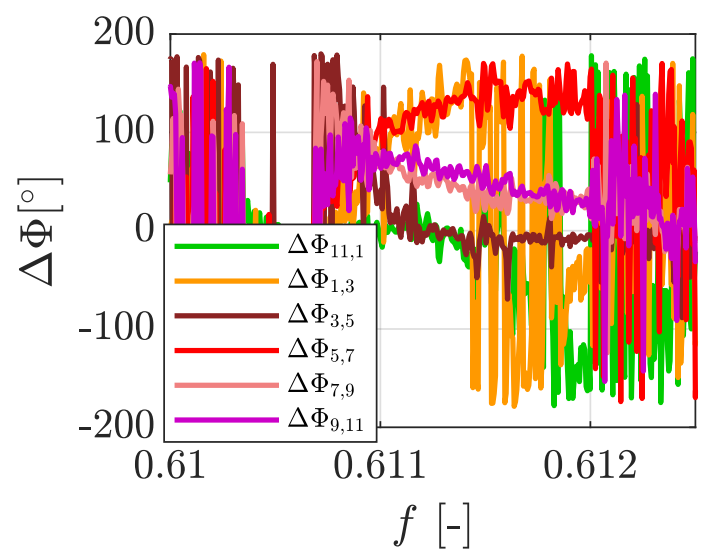

(b)

Figure 13. EO17: Frequency domain and phase lag. The same legends as displayed in Figure 7 apply. (a) Zoom on EO17 excited normalized amplitude of all SG-applied blades during rotational speed of M8EO24; (b) Zoom on EO17 excited phase lag $\Delta \Phi_{i, i+2}$ of all SG-applied blades during rotational speed of M8EO24.

The expected phase lag $\Delta \Phi_{i, i+2}$ during ND5 vibrations is $\pm 60^{\circ}$ (Table 2). This phase lag could only be measured between two out of the six SGs, namely $\Delta \Phi_{7,9}$ and $\Delta \Phi_{9,11} . \Delta \Phi_{i, i+2}$ between the other four blades is either $\approx 0^{\circ}$, or $\approx 120^{\circ}$, which would be the result of ND0, ND6 or ND4 vibrations, respectively. This behavior is expected, since the system of rotor blades is not an ideal system and the actual nodal diameter is a superposition of several ones Ref. [15]. Interestingly, these EO17 vibrations appear in the shaft as well (see Figure 14), and the phase lag $\Delta \Phi_{\mathrm{S}}$ almost exactly equals $60^{\circ}$.

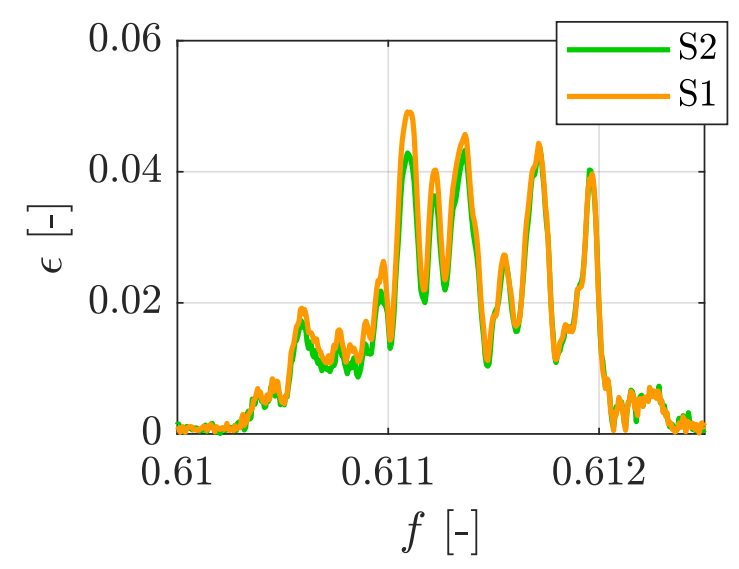

(a)

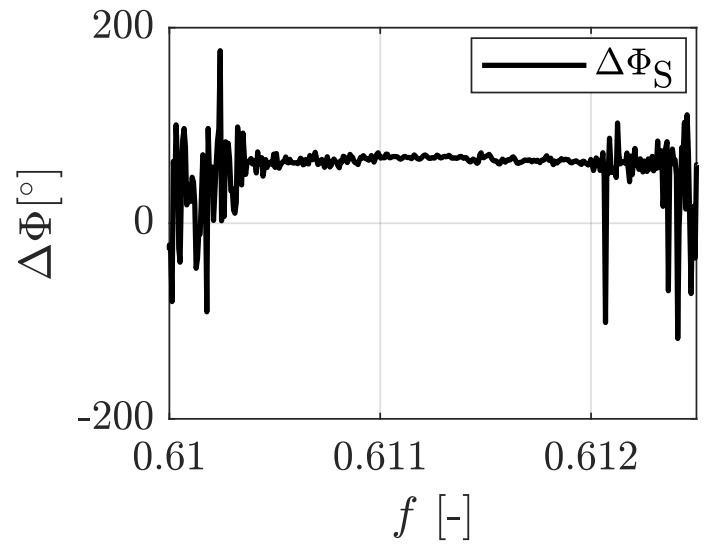

(b)

Figure 14. EO17: Shaft vibrations, frequency domain and phase lag. (a) Zoom on EO17 excited normalized amplitude of shaft SGs during rotational speed of M8EO24; (b) Zoom on EO17 excited phase lag $\Delta \Phi_{\mathrm{S}}$ of shaft SGs during rotational speed of M8EO24.

Those observations are supported by the analysis of additional EO16 vibrations, occurring at a rotational speed slightly above M9EO24. Here, EO16 appears in all blades (Figure 15), exciting M5 and resulting in small reactions in the shaft. A more prominent frequency content in the shaft again corresponds to EO17, but with much smaller resulting blade amplitudes. The number of diffuser vanes in the compressor equals 17, drawing an unexpected connection between the geometry of the turbocharger and the measured EO17 vibrations in the shaft and the rotor blades of the turbine. Further investigation regarding the appearance of EO17 will be necessary in the future, since this excitation order results in significant blade vibration amplitudes at unexpected rotational speeds. As of now, 
the origin of EO16 remains unclear, since no geometric feature of the turbocharger corresponds to this number directly.

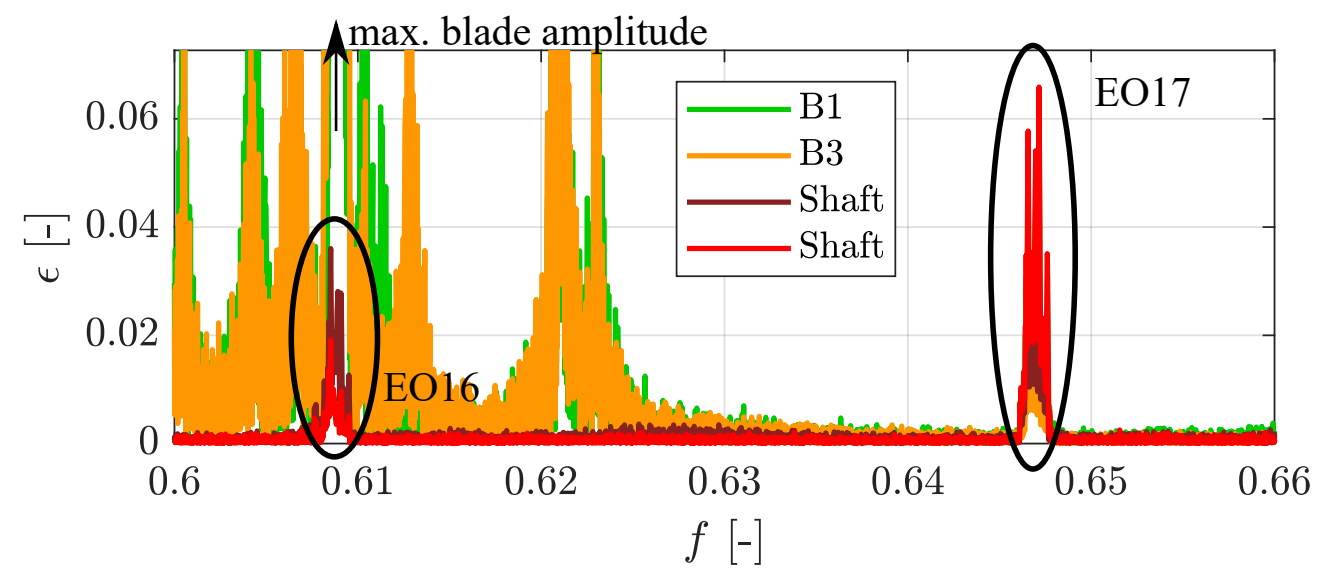

Figure 15. Zoom on EO16 and EO17 excited normalized amplitude of shaft and blade SGs during rotational speed of $\mathrm{M} 9 \mathrm{EO} 24$.

\section{Conclusions}

The applied pattern of strain gauges (one SG on every other blade around the circumference) has proven to be able to reliably detect points of blade resonance during ND0 vibrations. Even though measured phase lags of $\Delta \Phi_{i, i+2}=0^{\circ}$ may be the result of ND0 or ND6, strain data from the shaft of the turbocharger was used, to support the theoretically predicted ND0 pattern. Interestingly, in three out of four displayed vibration modes, resonance of all blades occurred at the same frequency and rotational speed, respectively. This may be the result of the strong physical coupling between the blades, due to the BLISK design of the rotor and the very stiff design of radial turbines as well. In general, resonance frequencies differ, but due to the ND0 blade vibration pattern in this case, the blade coupling seems to be promoted even more. The use of strain gauges on the shaft has provided some insight on the coupling between compressor and turbine wheel by means of the shaft. Measured EO17 vibrations in both the shaft and the blades are presumed to be the result of an excitation through interaction of compressor rotor and diffusor. Compared to other excitation orders, apart from EO24, EO17 shows the highest responses in the shaft, promoting the assumption that the shaft excites the blades in this case and not the other way around.

Author Contributions: Conceptualization, M.W. (Markus Wunderlich); methodolodgy, M.W. (Markus Wunderlich) and A.E.; software, M.W. (Markus Wunderlich); formal analysis, M.W. (Markus Wunderlich); investigation, M.W. (Markus Wunderlich) and A.E.; resources, M.W. (Manfred Wirsum); data curation, M.W. (Markus Wunderlich); writing-original draft preparation, M.W. (Markus Wunderlich); writing-review and editing, M.W. (Markus Wunderlich), A.E., M.W. (Manfred Wirsum) and K.B.; visualization, M.W. (Markus Wunderlich); supervision, M.W. (Manfred Wirsum); project administration, M.W. (Manfred Wirsum); funding acquisition, M.W. (Manfred Wirsum). All authors have read and agreed to the published version of the manuscript.

Funding: This research paper received no external funding.

Acknowledgments: The authors would like to thank the research association Forschungsvereinigung Verbrennungskraftmaschinen e. V. and the Association Industrial Research (AIF) for the financial support of this research project. The authors would also like to gratefully acknowledge Kompressorenbau Bannewitz $\mathrm{GmbH}$, whose support was essential for the present investigations.

Conflicts of Interest: The authors declare no conflict of interest. The above results are based on the experimental data collected as part of a research project Blade Forces (1189), 01.01.2015-31.12.2017. This research was funded by research association Forschungsvereinigung Verbrennungskraftmaschinen e. V. and the Association Industrial Research (AIF) under grant number: BMWi/IGF-Nr. 18568-N-. 


\section{Nomenclature}

$\begin{array}{ll}\text { BLISK } & \text { blade integrated disk } \\ \mathrm{B} i & \text { strain signal of } i \text { th blade } \\ \mathrm{EO} & \text { excitation order } \\ \Delta \Phi_{i, j} & \text { phase lag of strain signals on } i \text { th and } j \text { th blade } \\ \Delta \Phi_{\mathrm{S}} & \text { phase lag of strain signals on the shaft } \\ \epsilon & \text { normalized strain } \\ \mathcal{F} & \text { Fourier transform operator } \\ f & \text { normalized frequency } \\ \mathrm{FFT} & \text { fast Fourier transformation } \\ f_{\mathrm{M}} & \text { resonance frequency } k \text { th Mode } \\ k & \text { strain gauge sensitivity } \\ \mathrm{ND} & \text { nodal diameter } \\ N & \text { rotational speed } \\ \Omega & \text { normalized rotational speed } \\ \omega & \text { rotational speed } \\ \mathrm{S} 1, \mathrm{~S} 2 & \text { strain signal of shaft gauges } \\ T_{\text {in }} & \text { turbine inlet temperature } \\ T_{\text {Wall }} & \text { wall temperature (estimated by CFD) } \\ \text { IM, RE } & \text { imaginary and real part of a complex number } \\ \zeta_{k} & \text { blade damping coefficient } k \text { th Mode }\end{array}$

\section{References}

1. Kemp, N.H.; Sears, W.R. Aerodynamic Interference Between Moving Blade Rows. J. Aeronaut. Sci. 1953, 20, 585-597. [CrossRef]

2. Kemp, N.H.; Sears, W.R. The Unsteady Forces Due to Viscous Wakes in Turbomachines. J. Aeronaut. Sci. 1955, 22, 478-483. [CrossRef]

3. Klaus, M. Strömungsinduzierte Schaufelschwingungen in Radialturbinen mit beschaufeltem Spiralgehäuse: Zugl.: Karlsruhe, Univ., Diss, 2007; Forschungsberichte aus dem Institut für Thermische Strömungsmaschinen, Universität Karlsruhe (TH); Logos-Verl.: Berlin, Germany, 2007; Volume Bd. 33.

4. Janicki, G.; Pezouvanis, A.; Mason, B.; Ebrahimi, M.K. Turbine Blade Vibration Measurement Methods for Turbocharges. Am. J. Sens. Technol. 2014, 2, 13-19.

5. Beirow, B.; Kühhorn, A.; Nipkau, J. On the Influence of Strain Gauge Instrumentation on Blade Vibrations of Integral Blisk Compressor Rotors Applying a Discrete Model. In Proceedings of the ASME Turbo Expo 2009: Power for Land, Sea, and Air, Orlando, FL, USA, 8-12 June 2009; pp. 245-253.

6. Kreuz-Ihli, T.; Filsinger, D.; Schulz, A.; Wittig, S. Numerical and Experimental Study of Unsteady Flow Field and Vibration in Radial Inflow Turbines. J. Turbomach. 2000, 122, 247-254. [CrossRef]

7. Kreuz-Ihli, T. Strömungsinduzierte Schaufelschwingungen in Leitgitterlosen Radialturbinen. Ph.D. Thesis, TH Karlsruhe, Karlsruhe, Germany, 2001.

8. Wilson, A.; Utengen, T. Turbine Blade Dynamics and Blade-Vane Interaction in a Radial Inflow Turbine. Agard Conf. Proc. 1994, 537, 35-1-35-11.

9. Mueller, T.; Waldherr, C.; Kovachev, N.; Esper, A.; Wunderlich, M.; Lenzen, C. Blade Forces: FVV-Project No. 1189; Final Project Report BMWi/AiF 18568; FVV: Frankfurt am Main, Germany, 2018.

10. Hackenberg, H.P.; Hartung, A. An Approach for Estimating the Effect of Transient Sweep Through a Resonance. J. Eng. Gas Turbines Power 2016, 138, 082502. [CrossRef]

11. Kovachev, N.; Waldherr, C.U.; Mayer, J.F.; Vogt, D.M. Prediction of Aerodynamically Induced Blade Vibrations in a Radial Turbine Rotor Using the Nonlinear Harmonic Approach. J. Eng. Gas Turbines Power 2019, 141, 021007. [CrossRef] 
12. Waldherr, C.U.; Vogt, D.M. A Comparison of Two Reduced Order Methods for Probabilistic Mistuning Investigations. In Proceedings of the ASME 2017 Gas Turbine India Conference, Bangalore, India, 7-8 December 2017; p. V002T05A014. [CrossRef]

13. Singh, P.M.; Vargo, J.; Schiffer M.D.; Dello, D.J. SAFE Diagram-A Design and Reliability Tool for Turbine Blading; Turbomachinery Laboratories, Texas A\&M University: College Station, TX, USA, 1988. Available online: http:/ / hdl.handle.net/1969.1/163593 (accessed on 9 July 2020).

14. Allport, J.M.; Jupp, M.L.; Pezouvanis, A.; Janicki, G.W.; Pierończyk, A.I.; Day, A.J.; Olley, P.; Mason, B.; Ebrahimi, M.K. Turbocharger blade vibration: Measurement and validation through laser tip-timing. In 10th International Conference on Turbochargers and Turbocharging; Elsevier: London, UK, 2012; pp. 173-181.

15. Klauke, T. Schaufelschwingungen realer integraler Verdichterräder im Hinblick auf Verstimmung und Lokalisierung: Zugl.: Cottbus, Techn. Univ., Diss., 2007; Der Andere Verl.: Tönning, Germany, 2007.

(c) 2020 by the authors. Licensee MDPI, Basel, Switzerland. This article is an open access article distributed under the terms and conditions of the Creative Commons Attribution (CC BY-NC-ND) license (https://creativecommons.org/licenses/by-nc-nd/4.0/). 